\title{
Vertebral body stenting: a new method for vertebral augmentation versus kyphoplasty
}

\author{
Robert Rotter - Heiner Martin - Sebastian Fuerderer • \\ Michael Gabl · Christoph Roeder • Paul Heini • \\ Thomas Mittlmeier
}

Received: 19 July 2009/Revised: 1 February 2010/Accepted: 11 February 2010/Published online: 1 March 2010

(C) The Author(s) 2010. This article is published with open access at Springerlink.com

\begin{abstract}
Vertebroplasty and kyphoplasty are wellestablished minimally invasive treatment options for compression fractures of osteoporotic vertebral bodies. Possible procedural disadvantages, however, include incomplete fracture reduction or a significant loss of reduction after balloon tamp deflation, prior to cement injection. A new procedure called "vertebral body stenting" (VBS) was tested in vitro and compared to kyphoplasty. VBS uses a specially designed catheter-mounted stent which can be implanted and expanded inside the vertebral body. As much as 24 fresh frozen human cadaveric vertebral bodies (T11-L5) were utilized. After creating typical compression fractures, the vertebral bodies were reduced by kyphoplasty $(n=12)$ or by VBS $(n=12)$ and then stabilized with PMMA bone cement. Each step of the procedure was performed under fluoroscopic control and analysed quantitatively. Finally, static and dynamic biomechanical tests were performed. A complete initial
\end{abstract}

R. Rotter $(\bowtie) \cdot$ T. Mittlmeier

Department of Trauma and Reconstructive Surgery,

University of Rostock, 18055 Rostock, Germany

e-mail: robertrotter@yahoo.de

H. Martin

Institute for Biomedical Engineering, University of Rostock,

Rostock, Germany

S. Fuerderer

Klinik Mutterhaus der Borromaeerinnen, Trier, Germany

M. Gabl

Department of Neurosurgery, Sanatorium Kettenbruecke, Innsbruck, Austria

C. Roeder · P. Heini

Department of Orthopaedic Surgery, Inselspital,

Bern, Switzerland reduction of the fractured vertebral body height was achieved by both systems. There was a significant loss of reduction after balloon deflation in kyphoplasty compared to VBS, and a significant total height gain by VBS (mean $\pm \mathrm{SD}$ in $\%, p<0.05$, demonstrated by: anterior height loss after deflation in relation to preoperative height [kyphoplasty: $11.7 \pm 6.2$; VBS: $3.7 \pm 3.8$ ], and total anterior height gain [kyphoplasty: $8.0 \pm 9.4$; VBS: $13.3 \pm 7.6])$. Biomechanical tests showed no significant stiffness and failure load differences between systems. VBS is an innovative technique which allows for the possibly complete reduction of vertebral compression fractures and helps maintain the restored height by means of a stent. The height loss after balloon deflation is significantly decreased by using VBS compared to kyphoplasty, thus offering a new promising option for vertebral augmentation.

Keywords Vertebral body stenting - Vertebroplasty . Kyphoplasty · Osteoporosis · Vertebral compression fracture

\section{Introduction}

When the elderly complain about suddenly occurring nontraumatic back pain, they are frequently suffering from a compression fracture of an osteoporotic vertebral body [7, 14]. Minimally invasive procedures, such as vertebroplasty and kyphoplasty, are well-established for the treatment of vertebral compression fractures. However, procedural disadvantages of these surgical techniques are incomplete fracture reduction or a significant loss of the restored height after balloon deflation prior to cement injection, respectively. In order to avoid loss of height after balloon 
deflation, the concept of using an expandable scaffolding structure similar to vascular stents was developed [5], resulting in vertebral body stenting (VBS), utilizing a specially designed catheter-mounted stent which can be implanted extra- or transpedicularly and expanded with the use of an inflatable balloon inside the vertebral body.

The original treatment for osteoporotic compression fractures was vertebroplasty, the injection of polymethylmethacrylate (PMMA) bone cement into the compressed vertebral body, thus relieving pain caused by loss of height without restoring it [6].

Balloon kyphoplasty (BKP) was the next step in the technological evolution of treatment alternatives and is now widely used for vertebral fractures [10, 17]. It has not, however, been possible to achieve the spinal realignment that was originally expected, as the initial reduction achieved with the balloon tamp is largely lost after deflation [4, 23]. The loss of vertebral height following fracture reduction with the balloon tamp and its subsequent removal prior to filling the created cavity with bone cement, is a problem that has thus far not been resolved. In order to avoid this loss of height, a newer alternative has been developed, based on the principles of balloon kyphoplasty and vascular stenting. Using VBS, the stent remains within the newly created vertebral cavity so the balloon can be removed after deflation while preventing the vertebral body from collapsing, so that, in an ideal scenario, a virtually physiological vertebral body height and shape can be restored and preserved. The cavity is then filled with PMMA bone cement [9]. The primary benefit of cement augmentation for osteoporotic vertebral fractures is the nearly immediate pain relief in over $80 \%$ of cases, whereby patients can be quickly and easily mobilized [1, 17].

Biomechanical and clinical data show that hyperkyphotic posture leads to an increased fracture risk in the adjacent healthy vertebral levels $[11,16]$. This appears to be particularly relevant in a growing group of patients in whom vertebral fractures of several levels have been observed within a short period of time, leading to a rapidly progressing kyphosis [13]. This postural deterioration could eventually be stopped by restoring the height of fractured vertebrae and cementing several adjacent levels as a preventive measure [9]. As mentioned above, there is currently no effective technology that allows for the vertebral deformity to be fully corrected. The newly developed stenting method presented here allows the surgeon to apply the original conceptual goal of BKP while minimizing the mechanical effect of balloon deflation by intraoperative scaffolding means.

It was the aim of our study to examine the biomechanical in vitro behaviour of VBS compared to BKP in vertebral compression fractures.

\section{Materials and methods}

Specimens and experimental groups

Four intact fresh human cadaveric spines (T11-L5) were used in this study. Three of the donors were female and one was male. The average age of the donors was 62.3 years (55-65 years). The specimens had been stored at $-20^{\circ} \mathrm{C}$. To prepare for biomechanical testing, they were sealed in a double plastic bag and thawed in a water bath at $25^{\circ} \mathrm{C}$ for over $8 \mathrm{~h}$. Each specimen was radiographically screened to exclude abnormalities that might compromise the mechanical properties of the spine (standard lumbar spine X-ray, $100 \mathrm{~cm}$ focus-film distance, $47 \mathrm{kV}, 4 \mathrm{mAs}$ ). Bone mineral density (BMD) was determined in the postero-anterior and lateral projections on each vertebra, using Dual Energy X-ray Absorptiometry (DEXA) (Lunar Prodigy Primo, General Electrics, Chalfont St. Giles, Great Britain). Osteoporosis was defined according to World Health Organization (WHO) criteria-BMD of more than 2.5 standard deviations below the mean of a young healthy reference population of the same gender ("T-score") [15]. Overall, 12 pairs of adjacent vertebrae were tested and divided into two groups. The cranial vertebra of each pair was augmented by VBS, the caudal vertebra by BKP as control.

The VBS system consists of a balloon-expandable metal stent mounted on a balloon-catheter, of which two each are inserted bilaterally into the vertebral body and simultaneously inflated with contrast-saline solution, under pressures up to $30 \mathrm{~atm}$, to symmetrically expand both stents. The stent implants consist of a strong and ductile cobaltchromium alloy that is extensively used in coronary and peripheral artery stenting. The unexpanded stent $(\varnothing$ $4.2 \mathrm{~mm}$ ) comes along pre-crimped on the balloon, and is gradually expanded to its final large-diameter configuration, thanks to its laser-cut mesh pattern where individual $1 / 4 \times 1 / 2 \mathrm{~mm}$ thick struts keep spreading apart until fracture reduction is satisfying and/or the maximum diameter of $17 \mathrm{~mm}$ is reached. After the balloon-assisted stent expansion is sufficient and/or complete, the balloons are deflated and retrieved, leaving both stents behind to keep the restored height, and PMMA cement is injected into the cavities supported by the stent mesh structures to produce stent-reinforced cement implant within the treated vertebral body.

Fracture generation and instrumentation

The vertebrae were isolated and all soft tissues were removed. Thereafter, vertebral heights were measured at the right and left anterior, central and posterior locations of the vertebral body (values were averaged for each position). Measurements were made using a digital caliper 
(0.02 $\mathrm{mm}$ accuracy). The caudal endplates of the vertebrae were embedded into radiolucent PMMA (Beracryl; Troller Kunststoffe, Fulenbach, Switzerland). Vertebral compression fractures were performed using a universal material testing machine (MTS; Eden Prairie, MN, USA; $15 \mathrm{kN}$ load cell, measurement error: $0.03 \%$ ). Load was transferred by the pivot-mounted pressure plate on the superior vertebral endplate to allow a wedge compression of the anterior wall (Fig. 1). The vertebra was compressed with a $2 \mathrm{~mm} / \mathrm{min}$ load application velocity and the load-displacement diagrams were recorded with a sampling rate of $5 \mathrm{~Hz}$. The compression was continued under visual control (using digital caliper) until a compression of the anterior vertebral edge of more than $40 \%$ was reached, which corresponds to a wedge compression fracture classified according to Genant grade 3.

After generating vertebral compression fractures, the specific working cannulae of both systems were placed bipedicularly according to manufacturers" specifications under the fluoroscopic imaging guidance of a C-arm (Ziehm Vario 3D, Ziehm imaging, Nürnberg, Germany). After correct placement of working cannulae, the vertebrae were mounted into a custom made test device performing reduction tests under a constant axial preload of $110 \mathrm{~N}$.

Either VBS $(\varnothing 17 \mathrm{~mm}$ [diameter] $\times 15 \mathrm{~mm}$ [length], Synthes GmbH, Solothurn, Switzerland) or a kyphoplasty inflatable bone tamp/balloon (KyphX Xpander ${ }^{\circledR}$ 15/3; Kyphon Europe, Wezembeek-Oppem, Belgium) was inserted simultaneously on both sides and expanded by two surgeons simultaneously with contrast-saline solution. The re-alignment was continued until the vertebral body height was restored. The vertical displacement of the centre of the upper end plate was recorded digitally as well as by a

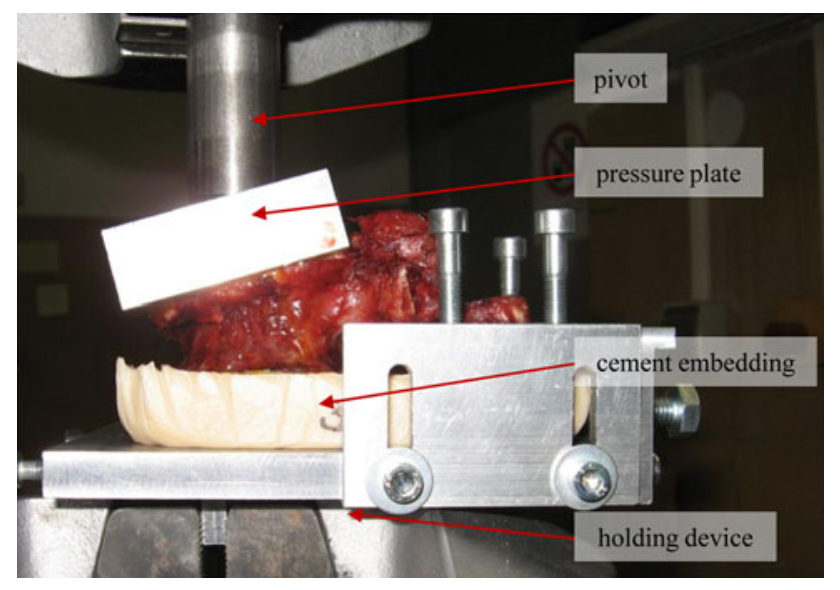

Fig. 1 Illustration of vertebra during fracture test in the material testing machine. The vertebral body, caudally embedded in PMMA, is placed in the holding device. Load is transferred by the pivot and the pressure plate on the upper vertebral body end plate. The holding device and the pivot are held by the hydraulic clamps of the material testing machine precision dial gauge. The maximum required inflation pressure and volumes were recorded.

After height restoration, the balloons were slowly deflated and removed. PMMA cement (Vertecem, Synthes) corresponding to the combined volume of the inflated balloons was inserted bilaterally, using working cannulae by Synthes or Kyphon to guarantee manufacturers' recommendations, respectively. Cement viscosity was measured a viscometer (Viscosafe, Synthes) before and during injection. Each step was performed under fluoroscopic control. Lateral fluoroscopic views were taken to determine the deformity corrections at the following time points: (1) after fracture generation and before reduction, (2) after maximum balloon inflation (VBS, Kyphon), (3) after balloon deflation and withdrawal, and (4) after injection and hardening of the cement. During the procedure the focusfilm distance was kept constant. To minimize possible magnification effects and interradiographic precision errors a defined standard (20 $\mathrm{mm}$ ball mounted at the test device) was visible in all radiographs. Anterior vertebral body height and kyphotic angle were analysed from these radiographs using a special software (Media Viewer 1.0; Ziehm Imaging, Nuernberg, Germany). Anterior vertebral height of the vertebra was defined as the distance between identical points on the superior and inferior endplates at the anterior location. The vertebral body kyphotic angle was defined by lines taken from the superior endplate of the vertebra to the inferior. Two surgeons performed these measurements. To guarantee intra- and inter-observer reproducibility of these measurements they were triplicated, and the mean value was calculated.

Following augmentation, all vertebrae were wet packed and stored at $25^{\circ} \mathrm{C}$ for $24 \mathrm{~h}$. Specimens were then reevaluated by CT for qualitative analysis of material distribution inside the vertebrae.

\section{Mechanical testing}

Two different biomechanical tests were performed by the material testing machine (MTS). The augmented vertebrae were loaded by cyclic sinusoidal dynamic compression to simulate behaviour of the candidate materials in the vertebra under respective loading conditions. For this purpose, 10,000 cycles were performed between $200 \mathrm{~N}$ and 2,000 N with a frequency of $1 \mathrm{~Hz}$. The fatigue tests were aborted if a central height loss of $5 \mathrm{~mm}$ was recorded or if damage to the vertebral body occurred. Applied force and resulting displacement were recorded simultaneously. From these curves the plastic deformation was measured. Plastic deformation was determined as the difference between vertebral height at the beginning of the test and after the last cycle. Hysteresis corresponded to the ability of the single vertebra to absorb energy during one cycle and was 
measured as the area between the compression and relaxation curves. Finally, all specimens were axially loaded in a displacement-controlled mode at a rate of $2 \mathrm{~mm} / \mathrm{min}$ until macroscopic failure of the vertebra occurred. Failure load and stiffness were measured and determined as follows: the failure load was defined manually at the first significant decrease of slope of the load displacement diagram. Vertebral stiffness was calculated from the first approximately linear range of the load displacement diagram and the slope of the corresponding regression line. All results were analysed separately and compared to each other.

\section{Statistical analysis}

All data were expressed as means $\pm \mathrm{SD}$. After proving the assumption of normality and equal variance across groups, differences between groups were assessed using ANOVA followed by the appropriate post hoc comparison test. Statistical significance was set at $p<0.05$. Statistics were performed using the software package SigmaStat (Jandel Corporation, San Rafael, CA, USA).

\section{Results}

Two spines were classified as osteoporotic, according to the WHO definition; one spine was classified as osteopenic. Only spine number 4 presented normal bone density values. After distribution of the vertebrae into the two groups, no significant difference was seen between BMD of the examined groups $(p=0.978)$ (Table 1).

\section{Results of fracture generation}

It was possible to generate a wedge compression fracture in all four specimens. The resulting vertebral stiffness $(p=0.743)$ and failure load $(p=0.703)$ values of the adjacent vertebrae were approximately equal and showed no significant differences (Table 1).

Results of instrumentation

Approach and placement of the bone tamps or stents in all vertebrae were carried out according to manufacturers' specifications. After augmentation the distribution of the cement in BKP and the VBS stent-cement composite in the vertebra was demonstrated by CT. Two material blocks were documented near to the sagittal line in the centre of the vertebra by both systems. Only a small amount of material was found below the end plates, as well as in the anterior quarter of the vertebral body. There was no difference in leakage in BKP compared to VBS (Fig. 2).

A complete reduction of vertebral body height was achieved with both systems while maintaining full balloon inflation, respectively. However, there was a significant loss of reduction after balloon deflation in BKP compared to VBS, and a significant total height gain by VBS (Fig. 3a). Anterior height loss after deflation in relation to preoperative height was significantly $(p=0.003)$ higher $(12 \%)$ in BKP compared to VBS (4\%). More relevant was the relation of anterior height loss after deflation to realignment height. Overall, there was a height loss of 58\% seen in BKP. VBS showed a significantly lower height loss of $21 \%(p<0.001)$. Correspondingly, there was a significant increase in total anterior height gain by VBS (13\%) compared to BKP (8\%) $(p=0.007)$ (Table 2). The mean changes of the kyphotic angles corresponded to the abovementioned results (Fig. 3b) (Table 2). Representative Xray images highlight the recent changes in height before and after deflation of the bone tamp in Fig. 4.

\section{Results of post-operative static and dynamic tests}

Post-operatively, there was a decrease in stiffness $(p=0.020)$ and an increase in failure load by BKP and VBS. The ratios of post-operative BKP and VBS stiffness and failure load to pre-operative stiffness and failure load displayed in percent are presented in Fig. 5 and Table 1. There was a significantly increased failure load $(p=0.044)$ in the augmented vertebra in comparison to the unmodified corresponding vertebra. These data show a tendency towards increased failure load for the VBS system $(182 \%)$ compared to BKP (164\%). However, there were no significant differences between the groups (stiffness $p=0.862$; failure load $p=0.592$ ).

After 10,000 cycles of axial compression, no significant difference was found between the groups in the subsidence behaviour (plastic deformation) of the vertebrae. In

Table 1 Summarized parameters after vertebral reduction and cementation

\begin{tabular}{llllllllll}
\hline $\begin{array}{l}\text { Failure load } \\
\text { preop (N) }\end{array}$ & $\begin{array}{l}\text { Failure load } \\
\text { postop (N) }\end{array}$ & $\begin{array}{l}\text { Stiffness } \\
\text { preop } \\
(\mathrm{N} / \mathrm{mm})\end{array}$ & $\begin{array}{l}\text { Stiffness } \\
\text { postop } \\
(\mathrm{N} / \mathrm{mm})\end{array}$ & $\begin{array}{l}\text { Stiffness ratio } \\
\text { postop/preop } \\
(\%)\end{array}$ & $\begin{array}{l}\text { Failure load } \\
\text { ratio postop/ } \\
\text { preop (\%) }\end{array}$ & $\begin{array}{l}\text { Cement } \\
\text { volume left } \\
(\mathrm{ml})\end{array}$ & $\begin{array}{l}\text { Cement } \\
\text { volume } \\
\text { right }(\mathrm{ml})\end{array}$ & $\begin{array}{l}\text { BMD DEXA } \\
\left(\mathrm{g} / \mathrm{cm}^{2}\right)\end{array}$ \\
\hline $\mathrm{BKP}$ & $3,246 \pm 1,546$ & $5,092 \pm 2,543$ & $2,075 \pm 618$ & $1,606 \pm 296$ & $84 \pm 32$ & $164 \pm 43$ & $3.3 \pm 1.0$ & $3.4 \pm 1.0$ & $0.580 \pm 0.179$ \\
$\mathrm{VBS}$ & $2,864 \pm 1,496$ & $4,702 \pm 2,244$ & $2,230 \pm 815$ & $1,490 \pm 344$ & $79 \pm 44$ & $182 \pm 56$ & $3.6 \pm 0.5$ & $3.3 \pm 0.6$ & $0.582 \pm 0.195$ \\
\hline
\end{tabular}

Data are given as mean $\pm \mathrm{SD}$ 
Fig. 2 Representative axial and coronal CT images following vertebrae augmentation. a VBS b BKP
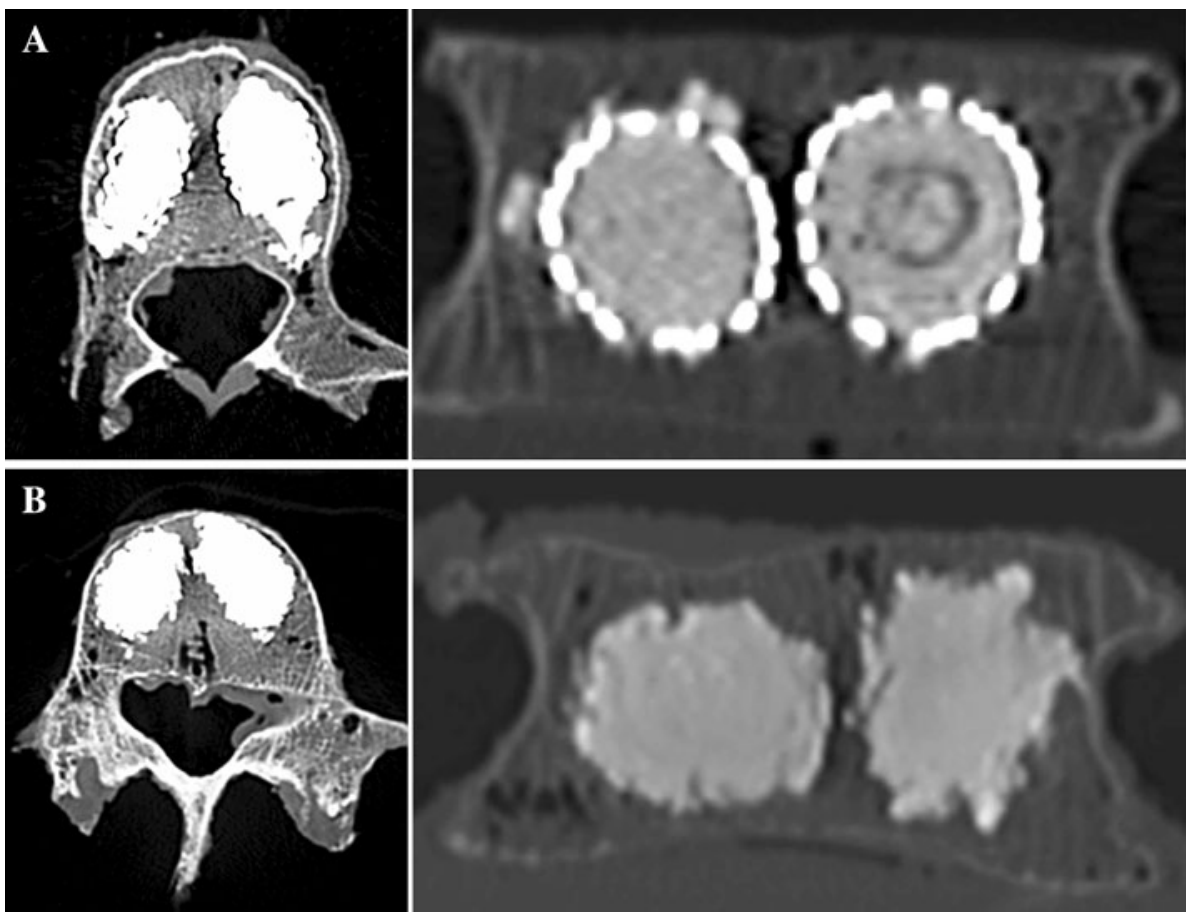

principle, the curves of the displacement time diagrams were characterized by an initial non-linear decrease of vertebral height loss followed by a phase of lower vertebral height loss. The hysteresis of the augmented vertebrae by BKP or VBS was not significantly different.

\section{Discussion}

Vertebroplasty and kyphoplasty are effective techniques for the relief of back pain in patients with osteoporotic compression fractures. Both procedures have the ability to reduce the kyphotic angle and restore vertebral height. Studies have demonstrated the ability of vertebroplasty to restore vertebral height to a certain degree $[3,18,21]$. Nevertheless, vertebroplasty has no intrinsic mechanical method to restore vertebral height but relies on patient positioning or the use of bolsters in the OR to induce lordosis. Kyphoplasty is able to restore vertebral height by means of a balloon tamp. However, clinically, 34\% of kyphoplasties do not result in an appreciable reduction in kyphotic angle or restoration of height [22]. One reason for inadequate height preservation in kyphoplasty is the loss of vertebral body height after balloon tamp deflation, prior to cement augmentation [4, 23]. Despite positioning the patient in a lordotic position (prone position with a concave curvature of the spine), compression forces of approximately $110 \mathrm{~N}$ are still exerted on the vertebrae and may contribute to the collapse of the created cavity [20,24]. The current study aims provide information about height restoration and static behaviour of vertebral compression
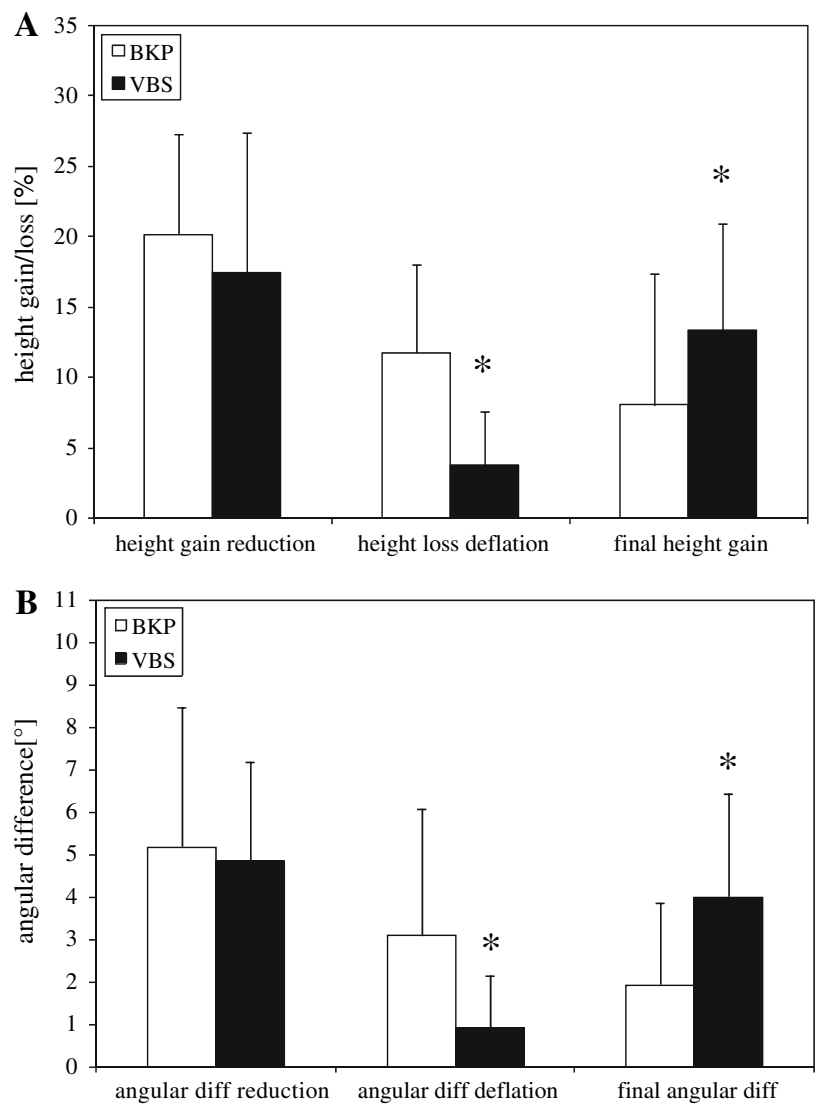

Fig. 3 Values of the relative height changes in percent (a) and angular changes in degree (b) under a constant preload of $110 \mathrm{~N}$ by VBS (filled squares) compared with BKP (open squares) (i) during complete reduction, (ii) after balloon deflation and (iii) resulting height gain/angular change after completion of reduction. Values are given as mean $\pm \mathrm{SD}$; ANOVA, post hoc comparison; * $p<0.05 \mathrm{BKP}$ 
Table 2 Summarized values of the change in vertebral anterior height and kyphotic angle during reduction procedure under constant preload $(110 \mathrm{~N})$

\begin{tabular}{lllllllll}
\hline $\begin{array}{l}\text { Height before } \\
\text { reduction }(\mathrm{mm})\end{array}$ & $\begin{array}{l}\text { Height gain } \\
\text { reduction } \\
(\mathrm{mm})\end{array}$ & $\begin{array}{l}\text { Height loss after } \\
\text { deflation }(\mathrm{mm})\end{array}$ & $\begin{array}{l}\text { Final height } \\
\text { gain }(\mathrm{mm})\end{array}$ & $\begin{array}{l}\text { Kyphotic angle } \\
\text { before reduction } \\
\left({ }^{\circ}\right)\end{array}$ & $\begin{array}{l}\Delta \text { Kyphotic } \\
\text { angle reduction } \\
\left({ }^{\circ}\right)\end{array}$ & $\begin{array}{l}\Delta \text { Kyphotic angle } \\
\text { after deflation }\left({ }^{\circ}\right)\end{array}$ & $\begin{array}{l}\Delta \text { Final } \\
\text { kyphotic } \\
\text { angle }\left({ }^{\circ}\right)\end{array}$ \\
\hline BKP & $19.7 \pm 2.6$ & $3.9 \pm 1.2$ & $2.2 \pm 1.1$ & $1.6 \pm 0.6$ & $10.2 \pm 6.0$ & $5.2 \pm 3.3$ & $3.1 \pm 3.0$ \\
VBS & $19.4 \pm 2.2$ & $3.3 \pm 1.8$ & $0.7 \pm 0.7^{*}$ & $2.6 \pm 0.4^{*}$ & $10.1 \pm 4.0$ & $4.8 \pm 2.3$ & $0.9 \pm 1.2^{*}$ & $4.0 \pm 2.4^{*}$ \\
\hline
\end{tabular}

Data are given as mean \pm SD. ANOVA, post hoc comparison

$* p<0.05 \mathrm{BKP}$

Fig. 4 BKP-representative (ac) and VBS-representative (d-f) lateral fluoroscopic images during vertebra augmentation under a constant preload of 110 N. a, d After fracture generation and before reduction; b, e after full balloon inflation; c, $\mathbf{f}$ after balloon deflation and removal
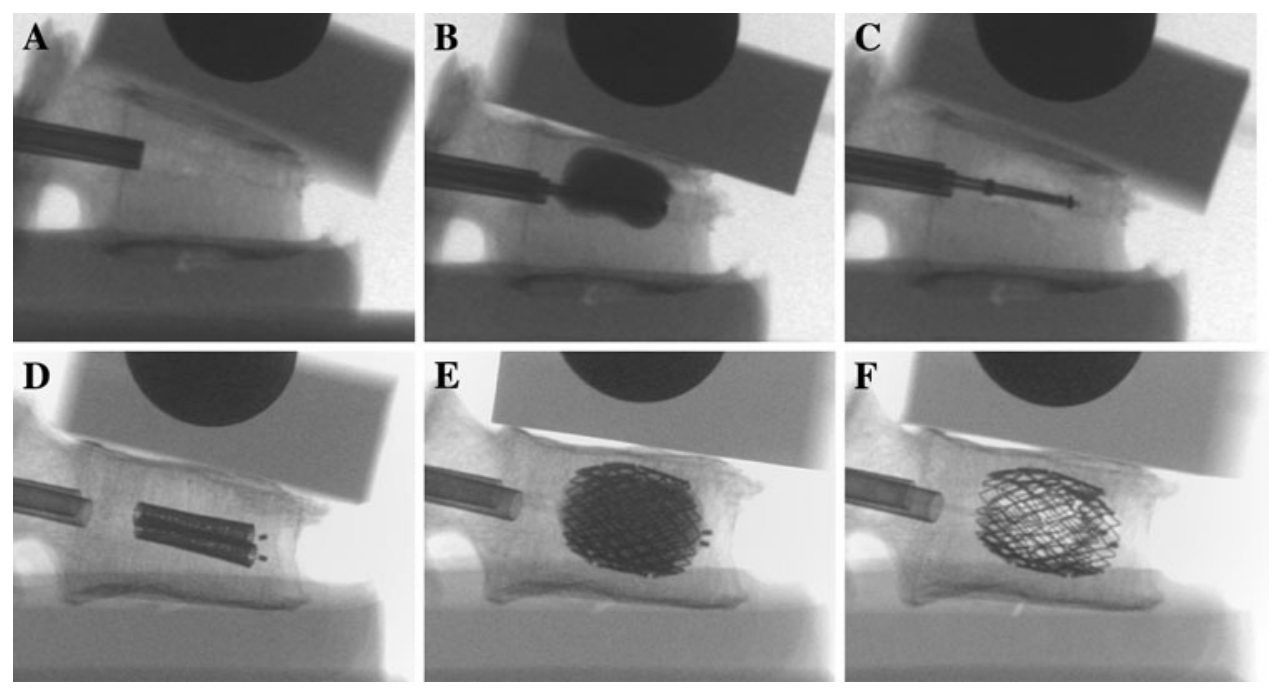

fractures following augmentation by vertebral body stenting compared to balloon kyphoplasty.

The most important finding of this study was the significantly lower height loss after balloon deflation when using VBS. A complete reduction of the fractured vertebral body height was achieved with both systems upon maximum balloon inflation. However, because of the intraoperative load-bearing capability of the stent, during VBS, there is a significantly higher preservation of initially gained height, as well as kyphotic angular changes of the vertebrae; the stent substantially retains the size of the created cavity inside the vertebra after balloon deflation. For VBS, the comparatively small anterior height loss after deflation to re-alignment height can be mainly attributed to the elastic recoil of the stent after balloon deflation, whereas, for BKP, this loss is much larger and is due to the absence of load-bearing means within the created cavity after balloon deflation and before cement injection and hardening.

To date, it could not yet be established with certainty, that height gain and improved re-alignment are clinically relevant. There is still a lack of randomized trials focussing on long-term results in vertebroplasty versus BKP and showing a significantly better outcome due to restored spinal alignment. Even a metaanalysis of 69 clinical studies by Hulme et al. has not shown a difference between vertebroplasty and BKP outcomes in the parameters pain relief, physical function, quality of life and adjacent fractures [12]. However, a biomechanical study of Rohlmann et al. [19] showed that the anterior shift of the upper body is the dominant factor in adjacent vertebral fractures. The advantage of BKP compared to vertebroplasty found in this study was apparent only if nearly full fracture reduction was achieved [19]. These data suggest that the difference in height gain between VBS and BKP can be clinically relevant.

In contrast to previous studies vertebrae were subjected to cyclic sinusoidal loading $[8,22]$. The cyclic loading tests were performed to simulate short and mid-term in vivo performance of the materials. According to the study of Wilke et al. [24], the upper load was defined at 2,000 N and the lower load at $200 \mathrm{~N}$. These test conditions should correspond to loading during activities of daily living. For our study, a fixed amount of cycles $(10,000)$ was used, although we are aware that in vivo long-term cyclic loading conditions cannot be achieved due to rapid degradation of the biological material. Hysteresis demonstrated no significant differences between the groups with regard to the plastic deformation of the vertebrae. This demonstrates the stabilizing effect of material injection in both groups. 


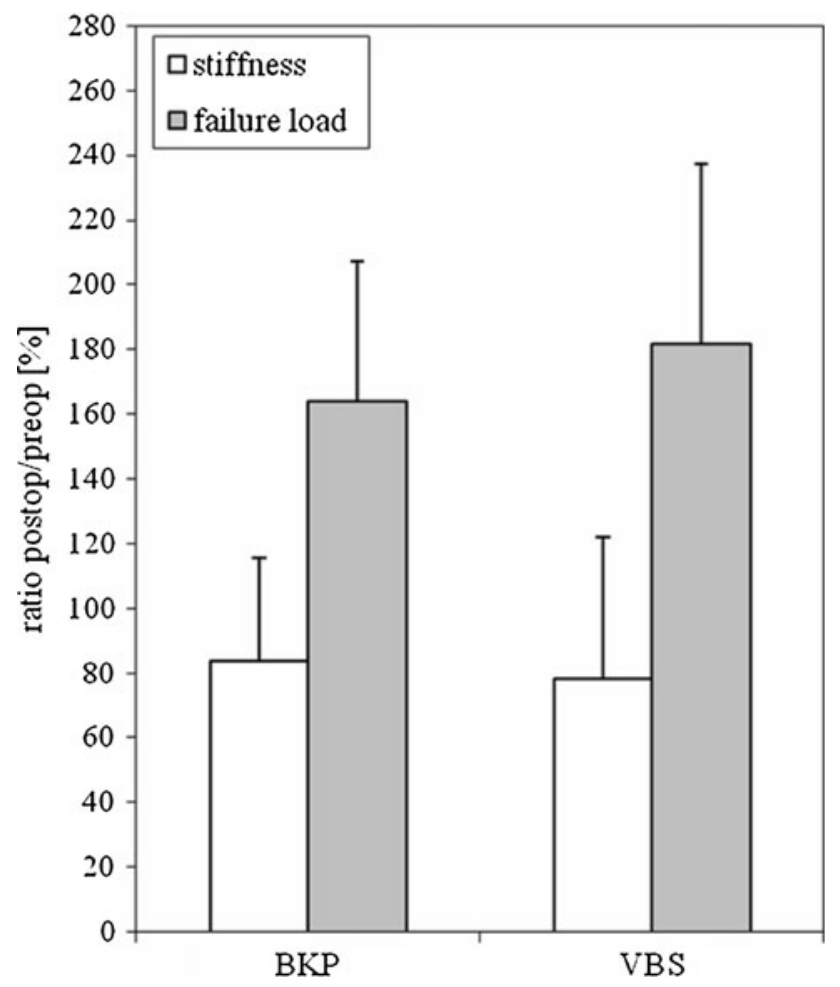

Fig. 5 Demonstrated are the results of the change in stiffness (open squares) and failure load (filled squares) in percent for BKP and VBS. The pre-operative stiffness and failure load were defined as $100 \%$. The post-operative data were set in relation to the pre-operative values. Values are given as mean $\pm \mathrm{SD}$

The examinations of static testing were carried out in correspondence to the criteria by Belkoff et al. and Heini et al. [2, 8]. In concordance with these authors, we found a significant difference in maximum failure load and a decreased stiffness between augmented and non-augmented vertebrae but no significant differences between VBS and BKP. However, there was a tendency of increased relative failure load by VBS. Significant differences in the filling degree of vertebrae could not be found between the groups (Table 1). Typically, in both groups, the main volume of material was located in two blocks near the sagittal line in the centre of the vertebra. There was no increase in stiffness seen in VBS and there were no differences in elastic deformation between both groups.

This biomechanical study, like others, was limited by the used fracture model and due to the experimental situation deviant from clinical reality. Inter- and intra-individual differences of the used spines where reduced by matching the vertebrae in pairs. However, the standardized distribution of VBS to the cranial and BKP to the caudal vertebra may have led to slightly increased absolute failure loads in BKP (Table 1). Nevertheless, this fixed protocol had no influence on the results of the reduction test and alterations between preoperative and postoperative biomechanical data. The instrumentation and augmentation of a single fractured vertebra, isolated from all soft tissue, is not similar to the clinical situation. However, the used preload of $110 \mathrm{~N}$ is comparable to the load ratio in prone position [2, 20, 24].

\section{Conclusion}

This in vitro study demonstrates that VBS is an innovative procedure which allows the possibly complete reduction of vertebral compression fractures due to the specific mechanical properties of an implanted permanent expandable stent. The height loss during reduction after balloon tamp deflation seen in BKP is significantly decreased following VBS, offering a promising new option for minimum invasive vertebral augmentation. However, the true value of this treatment must be shown in clinical trials.

Acknowledgments The authors cordially thank the engineers of Synthes GmbH, Oberdorf, Switzerland for their generous assistance. This study was supported in part by Synthes GmbH, Solothurn, Switzerland.

Open Access This article is distributed under the terms of the Creative Commons Attribution Noncommercial License which permits any noncommercial use, distribution, and reproduction in any medium, provided the original author(s) and source are credited.

\section{References}

1. Alvarez L, Alcaraz M, Perez-Higueras A, Granizo JJ, de Miguel I, Rossi RE, Quiñones D (2006) Percutaneous vertebroplasty: functional improvement in patients with osteoporotic compression fractures. Spine 31:1113-1118

2. Belkoff SM, Mathis JM, Fenton DC, Scribner RM, Reiley ME, Talmadge K (2001) An ex vivo biomechanical evaluation of an inflatable bone tamp used in the treatment of compression fracture. Spine 26:151-156

3. Carlier RY, Gordji H, Mompoint DM, Vernhet N, Feydy A, Vallée C (2004) Osteoporotic vertebral collapse: percutaneous vertebroplasty and local kyphosis correction. Radiology 233:891898

4. Feltes C, Fountas KN, Machinis T, Nikolakakos LG, Dimopoulos V, Davydov R, Kassam M, Johnston KW, Robinson JS (2005) Immediate and early postoperative pain relief after kyphoplasty without significant restoration of vertebral body height in acute osteoporotic vertebral fractures. Neurosurg Focus 18:5

5. Fürderer S, Anders M, Schwindling B, Salick M, Düber C, Wenda K, Urban R, Glück M, Eysel P (2002) Vertebral body stenting. A method for repositioning and augmenting vertebral compression fractures. Orthopade 31:356-361

6. Galibert P, Deramond H, Rosat P, Le Gars D (1987) Preliminary note on the treatment of vertebral angioma by percutaneous acrylic vertebroplasty. Neurochirurgie 33:166-168

7. Gold DT (1996) The clinical impact of vertebral fractures: quality of life in women with osteoporosis. Bone 18:185-189 
8. Heini PF, Berlemann U, Kaufmann M, Lippuner K, Fankhauser C, van Landuyt P (2001) Augmentation of mechanical properties in osteoporotic vertebral bones-a biomechanical investigation of vertebroplasty efficacy with different bone cements. Eur Spine J 10:164-171

9. Heini PF, Orler R (2004) Vertebroplasty in severe osteoporosis. Technique and experience with multi-segment injection. Orthopade 33:22-30

10. Hillmeier J, Grafe I, Da Fonseca K, Meeder PJ, Nöldge G, Libicher M, Kock HJ, Haag M, Kasperk C (2004) The evaluation of balloon kyphoplasty for osteoporotic vertebral fractures. An interdisciplinary concept. Orthopade 33:893-904

11. Huang MH, Barrett-Connor E, Greendale GA, Kado DM (2006) Hyperkyphotic posture and risk of future osteoporotic fractures: the Rancho Bernardo study. J Bone Miner Res 21:419-423

12. Hulme PA, Krebs J, Ferguson SJ, Berlemann U (2006) Vertebroplasty and kyphoplasty: a systematic review of 69 clinical studies. Spine 31:1983-2001

13. (2002) Incidence of vertebral fracture in Europe: results from the European Prospective Osteoporosis Study (EPOS). J Bone Miner Res 17:716-724

14. Kado DM, Browner WS, Palermo L, Nevitt MC, Genant HK, Cummings SR (1999) Vertebral fractures and mortality in older women: a prospective study. Study of Osteoporotic Fractures Research Group. Arch Intern Med 159:1215-1220

15. Kanis JA, Melton LJ 3rd, Christiansen C, Johnston CC, Khaltaev N (1994) The diagnosis of osteoporosis. J Bone Miner Res 9:1137-1141
16. Keller T, Kosmopoulos V, Liebschner M (2003) Modelling of bone damage and fracture in osteoporosis. In: Spalzki M, Gunzburg R (eds) Vertebral osteoporotic compression fractures. Lippincott, Philadelphia, pp 35-50

17. Ledlie JT, Renfro MB (2006) Kyphoplasty treatment of vertebral fractures: 2-year outcomes show sustained benefits. Spine 31:57-64

18. McKiernan F, Jensen R, Faciszewski T (2003) The dynamic mobility of vertebral compression fractures. J Bone Miner Res 18:24-29

19. Rohlmann A, Zander T, Bergmann G (2006) Spinal loads after osteoporotic vertebral fractures treated by vertebroplasty or kyphoplasty. Eur Spine J 15:1255-1264

20. Sato K, Kikuchi S, Yonezawa T (1999) In vivo intradiscal pressure measurement in healthy individuals and in patients with ongoing back problems. Spine 24:2468-2474

21. Teng MM, Wei CJ, Wei LC, Luo CB, Lirng JF, Chang FC, Liu CL, Chang CY (2003) Kyphosis correction and height restoration effects of percutaneous vertebroplasty. AJNR Am J Neuroradiol 24:1893-1900

22. Tohmeh AG, Mathis JM, Fenton DC, Levine AM, Belkoff SM (1999) Biomechanical efficacy of unipedicular versus bipedicular vertebroplasty for the management of osteoporotic compression fractures. Spine 24:1772-1776

23. Voggenreiter G (2005) Balloon kyphoplasty is effective in deformity correction of osteoporotic vertebral compression fractures. Spine 30:2806-2812

24. Wilke HJ, Neef P, Caimi M, Hoogland T, Claes LE (1999) New in vivo measurements of pressures in the intervertebral disc in daily life. Spine 24:755-762 